\title{
INDEPENDENT EVOLUTION OF VESSELS IN GNETALES
}

\section{AND ANGIOSPERMS \\ W. P. ТномР о \\ (WITH ELEVEN FIGURES)}

The possession of vessels by both angiosperms and Gnetales is perhaps the strongest argument, both of those botanists who believe that the angiosperms have been derived from Gnetales, and of those who maintain that the two groups have descended from a common ancestor. It has therefore received much emphasis in all discussions of the origin of angiosperms and of the affinities of the Gnetales. The emphasis which it has received, however, is out of all proportion to the actual study of the vessels themselves.

In a systematic study of the anatomy of the Gnetales (4) which the writer is carrying on, overwhelming evidence has accumulated that, although the completed vessels of the two groups bear a remarkable resemblance to each other, nevertheless their mode of development and their actual origin have been quite distinct in the two groups. In other words, we have in the case of these vessels another of the baffling examples of parallel development.

\section{Evolution of Gnetalean vessel}

The typical vessel of Ephedra, the most primitive of the Gnetales, is characterized by the occurrence on its end wall of several or many large bordered pits which lack the middle lamella and in which the bordering area is narrow. The end of such a vessel is shown in radial section in fig. $I$ and in tangential section in fig. 2. The figures show that this type of vessel differs from the familiar angiospermic type in having several small bordered perforations in place of the single large one of the higher type. Boodue and Worsdell (I), and the writer (4), have shown how this Ephedra type of vessel has been evolved from the ordinary tracheid of the coniferous type. The changes involve (I) the enlargement of the whole element, (2) the enlargement of several of the bordered pits 
on the oblique end wall, (3) the reduction in the border of these pits,

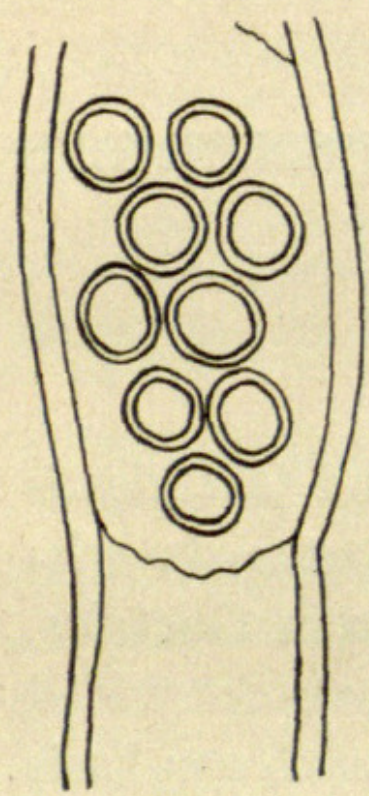

Fig. I

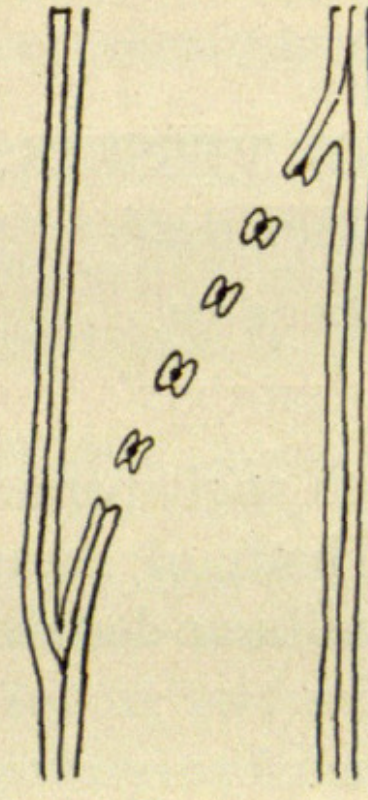

Fig. 2
Figs. I, 2.-Typical vessels from Ephedra monostachya: fig. I, radial; fig. 2, tangential section; all figs. $\times 250$.

is not often seen, but various bordered pits and perforations are common in conservative regions. Fig. 4 represents a tangential view of a similar end wall and shows clearly the relationship between perforations and bordered pits. For further details of the process the reader is referred to the previous article by the writer (4).

The typical vessel of Gnetum, the highest of the Gnetales, differs from that of Ephedra in having a single large oval or elliptical perforation instead of several circular ones (fig. 5). It is, in other words, like the highest angiospermic type except that as a rule it exhibits a narrow border. Even this and (4) the disappearance of the tori and middle lamellae. In conservative regions of Ephedra ${ }^{\mathrm{I}}$ all stages in these processes may be found; in other. words, there are all gradations between tracheids and vessels. Fig. 3 represents the radial view of the end of a vessel from the young wood of Ephedra monostachya. At the very end are typical bordered pits and higher up are seen stages in their transformation into perforations of the ordinary Ephedra kind. Such a gradual transformation intermediate conditions between

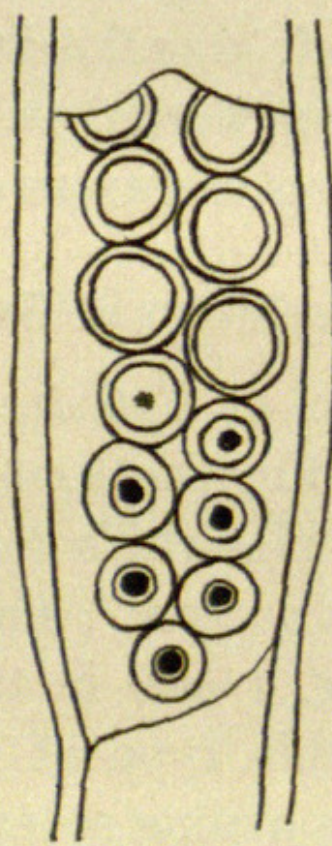

FIG. 3

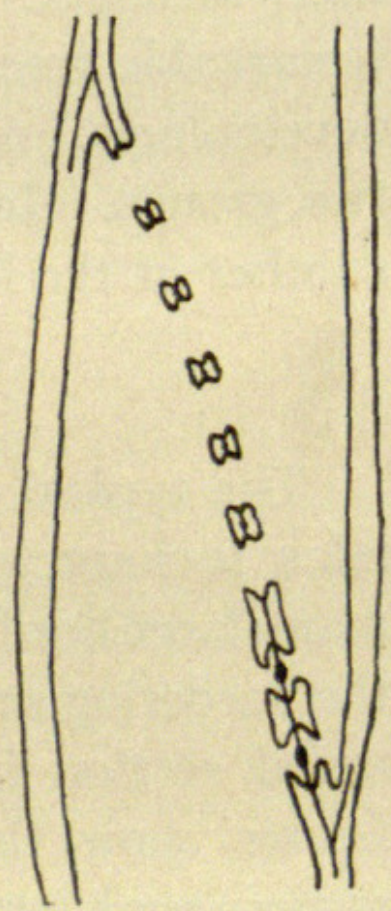

Fig. 4
Figs. 3, 4.-Vessels from Ephedra monostachya, showing relationship between perforations and bordered pits.

${ }^{x}$ Young stem and root, node, seedling, etc. 
border may disappear, however, in the old wood of large trees. In spite of the great differences between the typical vessels of Gnetum and those of Ephedra, a comparative study of the conservative regions of many species of the former has shown that the Gnetum type undoubtedly has been derived from the Ephedra type and has revealed the course of its evolution.

In such regions of Gnetum the Ephedra type of vessel is of common occurrence, as has been noted by Duthie (2) and the writer (5). Such a vessel from the young root of a seedling of G. Gnemon is shown in fig. 6. Another vessel is shown in tangential view in fig. 7 . In this vessel even the relationship to bordered pits is shown. While

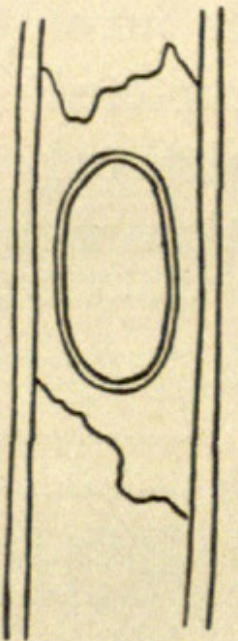

Fig. 5.-Typical vessel of Gnetum. Gnetum naturally does not show the transitions to tracheids as well as Ephedra, nevertheless intermediate conditions may easily

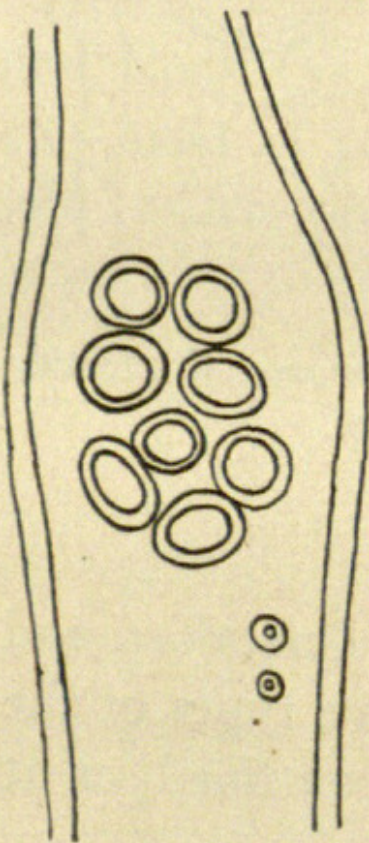

FIG. 6

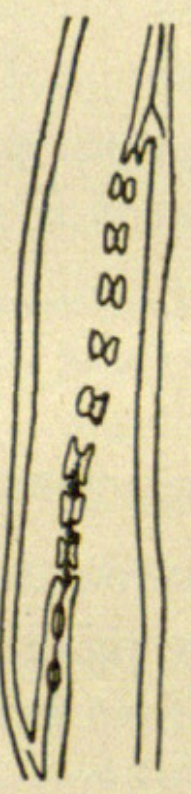

FIG. 7
Figs. 6, 7.-Fig. 6, vessel from root of seedling of Gnetum Gnemon: note that it is of the type characteristic of Ephedra; fig. 7 , tangential section of vessel similar to that shown in fig. 6 . be found. In some species of Gnetum the type of vessel characteristic of Ephedra is much more common than in others, and within the same species it is more common in certain conservative regions and certain individual specimens than in others.

The way in which the Gnetum type of vessel has been evolved from the Ephedra type is easily observed in such regions and is illustrated in fig. 8 . The changes involve the further enlargement of the individual perforations and the disappearance of the portions of the wall between them. In this way the several perforations fuse in a single large one. In fig. $8 a$ three of the perforations near the top have fused into a common opening, although parts of their original outlines are still distinct. Near the bottom two pits have fused in similar fashion. At two points (one near the top and the other near the middle) it may be observed that 
the pits have fused on the side of one element but not on the side of the other. In fig. $8 c$ all have fused in a common perforation on one side but only in groups on the other. In fig. $8 d$ the process is nearly completed, the indications of the individual perforations being visible only along the left side. In different vessels all sorts of conditions with respect to the fusion of perforations may be observed. In some cases they first fuse horizontally and in some cases vertically.

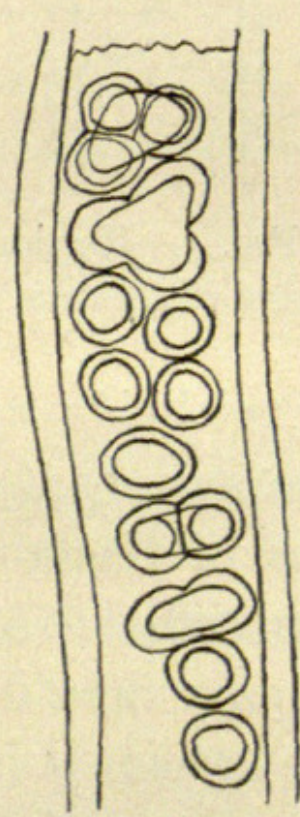

$a$

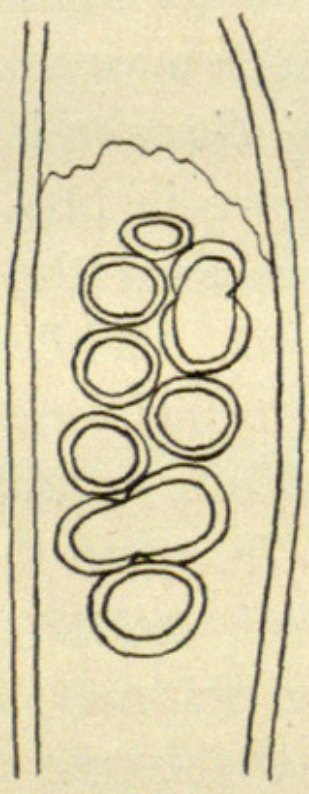

b

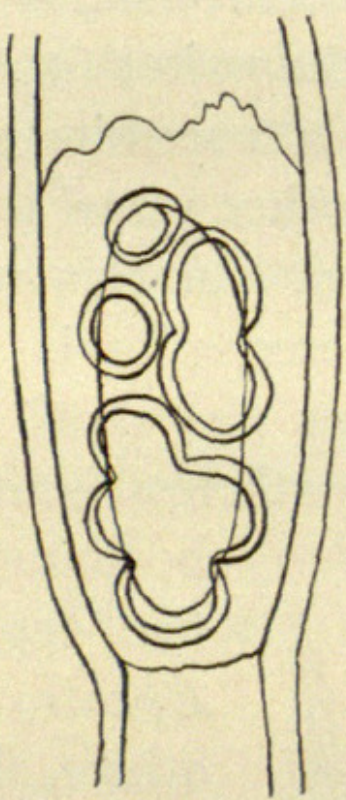

C

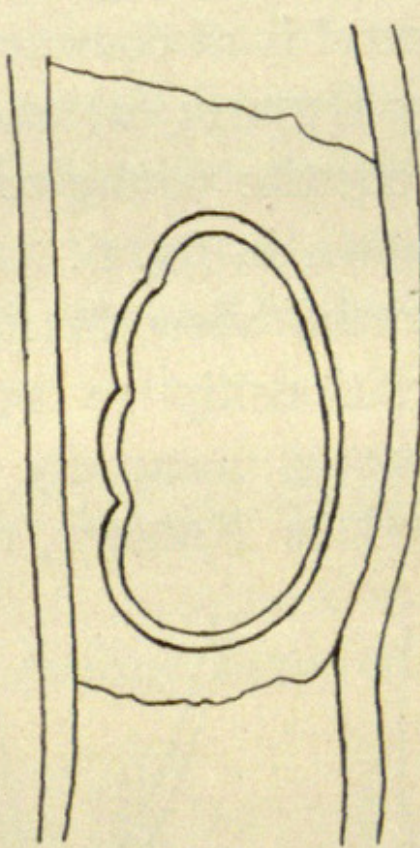

$d$

FIG. 8.-Series of vessels from node of seedling of Gnetum moluccense, illustrating transitional stages between Ephedra type and Gnetum type of vessel.

\section{Evolution of the angiospermic vessel}

If there is any genetic relationship between the Gnetalean and angiospermic vessels, we should find in the primitive types of the latter a course of development similar to that just outlined, or at least some vestiges of the Gnetalean condition.

The primitive type of angiospermic vessel is undoubtedly the so-called scalariform kind (illustrated in fig. 9 from the wood of Betula lutea). The most advanced type is the familiar porous kind with a single large perforation (fig. ro). In the scalariform type the perforation of the end wall is crossed by a large number of parallel horizontal bars, or, in other words, there are many horizontally elongated perforations. The outline of the whole perforated area is similar in shape and size to the single perforation of 
the higher type. It is not my intention to discuss the origin of this scalariform vessel in detail. It may be pointed out, however, that such an end wall may have developed in one of two ways.

(I) The scalariform perforations may be modifications of the scalariform bordered pits characteristic of the primary tracheids of all vascular plants and of the secondary tracheids of many ancient forms (Lepidodendron, Calamites, Bennettitales, etc). If this alternative is the correct one, we have in the angiospermic vessel of this type a retention of a very primitive form of pitting which has disappeared from the secondary tracheids of all plants above the cycads with the possible exception of such plants as Trochodendron, Tetracentron, etc. (6). With the exception of these perforations it is also

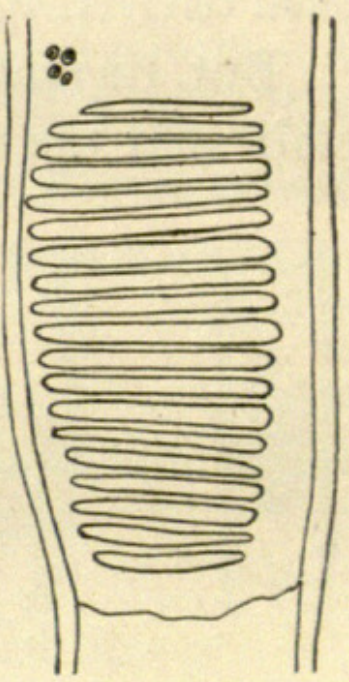

FIG. 9.-Scalariform vessel of birch. absent from the vessels of all angiosperms, although JEFFREY and Cole (3) regard as vestiges of vessels certain elements with this kind of pitting which they have found in wounded Drimys and which occur normally in Trochodendron and Tetracentron. According to one alternative, therefore, the angiospermic vessel has

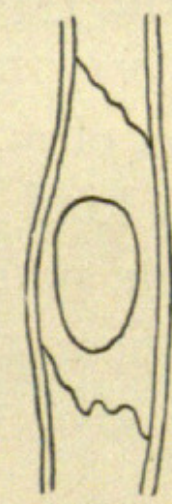

Fig. I0.-Typical angiospermic vessel from Vaccinium corymbosum. been produced when the scalariform bordered pits on the end wall of a tracheid lost their membranes and became perforations. At the same time the pits of the lateral walls were transformed into the familiar crowded circular type.

(2) On the other hand, the scalariform perforations may have resulted from the fusion of pits of the ordinary circular multiseriate type. In many angiospermic woods all gradations may be observed between scalariform and multiseriate circular pitting. If this alternative is correct, the angiospermic vessel has not been derived from the primitive tracheid with scalariform pits, but from the higher ordinary type of tracheids with circular bordered pits. The perforations are therefore not retentions but new productions. It 
should be pointed out that on the basis of the first alternative the transitions between multiseriate and scalariform pitting are to be interpreted in the reverse direction, the multiseriate pits having been derived from the scalariform.

But, no matter which of these two views is the correct one, it is plain that the vessel with the scalariform end wall is the primitive

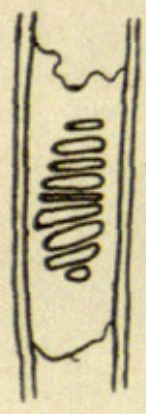

$a$
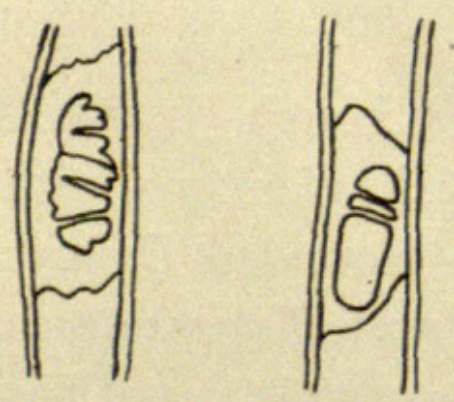

$e$

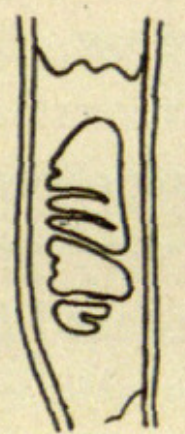

c
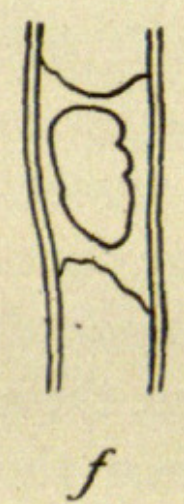

Fig. 11.-Series of vessels from wood of Vaccinium corymbosum, illustrating transformation of scalariform perforations into single large perforation.

kind in angiosperms. One evidence that this is true is the fact that it prevails in those angiosperms which are admittedly primitive, whereas the type with the single large perforation prevails in the higher forms. Sometimes the two types are found in different members of the same family, but in such cases the more primitive members of the family are characterized by the possession of the scalariform type, while the higher members have the singly perforated type.

That the scalariform type of vessel is the primitive one is further shown by cases of actual transformation of this kind into the kind with the single perforation. Not only do these cases prove the primitiveness of the former, but they also give us a picture of the evolution of the single perforation.

Some years ago the writer discovered in the wood of Vaccinium all transitions between the scalariform perforations and the single large perforation. The process consists simply of the gradual loss of the bars. Some stages are represented in fig. II. A typical scalariform vessel is shown in $a$; in $b$ two bars remain intact, two more are incomplete, and the positions of others are indicated by the projections from the sides. Random samples further illustrating the process are represented in $c$ and $d$. In $f$ the process is nearly 
completed, the positions of three bars being indicated by projections. In the wood of different species of Vaccinium innumerable conditions similar to these may be found side by side. I have been careful to determine that none of these cases are due to imperfect sectioning, but that they represent the actual state of affairs. This has been done by means of careful series of sections in celloidin. Moreover, views like $e$, which are common, could not be produced by the carrying away of the bars in sectioning, for in that case the margin of the perforation would not be smooth, but would show where the bars had been broken. From these facts it is clear that the angiospermic vessel with the single large perforation has been derived from that with the scalariform perforations.

\section{Comparison of evolution of Gnetalean with that of angiospermic vessels}

We have seen that the single large perforation of the Gnetalean vessel has been produced by the fusion of several perforations derived from circular bordered pits. We have also seen that the similar single large perforation of the angiospermic vessel has been evolved from the scalariform type. Evidently, therefore, the two are not genetically related. In the evolution of the Gnetalean vessel there is and can be no scalariform stage. The Gnetalean vessel usually has only two rows of circular pits and never more than three. Consequently, no matter how the fusions take place, no scalariform bars can result. The Gnetalean and angiospermic vessels may or may not have been derived from the same type of element, but from the very beginning the evolution of the two has taken place along entirely different lines. In the Gnetalean line a few circular bordered pits, haphazardly arranged, have enlarged and fused in a single perforation; in the angiospermic line long narrow parallel slits, which have been retained or evolved, have fused to form a similar single perforation.

\section{Conclusions}

From these considerations it follows that the vessel of Gnetum should disappear from all discussions of the origin of angiosperms. The possession of vessels by the two groups can no longer be used 
as a demonstration or even as evidence of genetic connection between them; it is rather to be used as a remarkable illustration of development by different plants of the same highly specialized structure. It is to be compared with the independent evolution in lycopods, horsetails, and ferns of similar seedlike structures. To what extent this applies to other points of resemblance between Gnetales and angiosperms is reserved for future discussion.

\section{Summary}

I. The vessel of Gnetum with the single large perforation in its end wall has been evolved by the enlargement and fusion of several haphazardly arranged bordered pits.

2. The vessel of angiosperms with the similar single large perforation has been evolved from the type with many long, narrow, scalariform perforations.

3. On account of the entirely different courses of evolution by which they were produced, there can be no genetic connection between the vessels of the two groups. They furnish a remarkable illustration of independent development of similar structures.

4. The possession of vessels by both angiosperms and Gnetales cannot be used as an argument in favor of the derivation of angiosperms from Gnetales or of both from common ancestors.

\section{UNIVERSITY OF SASKATCHEWAN}

SaSkatoon, SaSk.

\section{LITERATURE CITED}

r. Boodle L. A., and Worspell, W. C., Some points in the anatomy of Casuarinaceae and Gnetaceae. Ann. Botany 8:231-264. I894.

2. Duthie, A. V., The anatomy of Gnetum africanum. Ann. Botany 27:593602. 1912.

3. Jefrrey, E. C., and Cole, R. D., Experimental investigations on the genus Drimys. Ann. Botany 30:359-369. I916.

4. Thompson, W. P., Anatomy and relationships of Gnetales I. Ephedra. Ann. Botany 27:1077-Iro4. I912.

5. - Morphology and affinities of Gnetum. Amer. Jour. Bot. 3:135-184. I9I6.

6. Thompson, W. P., and Barley, I. W., Are Tetracentron, Trochodendron, and Drimys specialized or primitive types? Mem. N.Y. Bot. Gard. 6: I9r6. 


\section{$2 \mathrm{BHL}$ Biodiversity Heritage Library}

Thompson, W. P. 1918. "Independent Evolution of Vessels in Gnetales and Angiosperms." Botanical gazette 65(1), 83-90. https://doi.org/10.1086/332191.

View This Item Online: https://www.biodiversitylibrary.org/item/109339

DOI: https://doi.org/10.1086/332191

Permalink: https://www.biodiversitylibrary.org/partpdf/223964

\section{Holding Institution}

Missouri Botanical Garden, Peter H. Raven Library

\section{Sponsored by}

Missouri Botanical Garden

\section{Copyright \& Reuse}

Copyright Status: Public domain. The BHL considers that this work is no longer under copyright protection.

This document was created from content at the Biodiversity Heritage Library, the world's largest open access digital library for biodiversity literature and archives. Visit BHL at https://www.biodiversitylibrary.org. 